\title{
Editorial
}

\section{OUR MISSION STATEMENT}

It is with great pleasure that we bring you the inaugural issue of Journal of Building Appraisal. Three major, interconnecting factors led to the launch and publication of this Journal. The first is the feedback that we received from practitioners, most notably their immense frustration that there was no high quality, peer-reviewed journal on building appraisal which was both practical and affordable. There are of course a great many trade magazines and academic journals which serve their respective readerships very well, but the absence of a detailed, professional journal, which bridges the gap between the two, meant that the profession lacked a publication which adequately reflected the evolving needs and concerns of those actively engaged in the appraisal of buildings: the building surveyor, structural engineer, building services engineer and building control surveyor, not to mention contractors, lawyers and architects.

Secondly, is the enormous pressure on building appraisers to keep in touch with the ever growing mass of new developments, best practice techniques, legal and regulatory updates, newly available instrumentation, reference guides, research, technical data and changes in costs of building materials to name but a few. Not only is this pressure acute, but the number of sources of information available to the building appraiser is bewildering. The need for a forum in which the most critical issues facing the industry are identified and analysed in detail became abundantly clear.

As if that were not enough, a third factor is acting as a catalyst for both of the above - the emerging requirements of the new Home Condition Reports and the knowledge consequently required by those seeking to qualify as Home Inspectors. With an estimated 7,500 Home Inspectors needed by 2006 to undertake home inspections and write Home Condition Reports, ${ }^{1}$ the impact on the industry, and the subsequent need for a tool to aid both professional development and students new to the profession, is unavoidable.

Journal of Building Appraisal has been launched to meet precisely these needs and aims to be the leading professional journal for all those undertaking or advising on the diagnosis of defects and the condition of buildings. Much as was our intention when we were the original publisher of Structural Survey (until 1993), our purpose, put simply, is to provide building appraisers with authoritative guides to the latest thinking and best practice in all the key topics in the field including building surveys; instrumentation and its use; defect investigation; insurance assessment and claims; maintenance; project management and monitoring; dilapidations; professional liability; building regulations; construction standards; dispute resolution; refurbishment; repairs and remedial works. Both residential and commercial property are covered in depth by the Journal, as are the specific issues affecting properties from all eras ranging 
from historic buildings and their preservation to modern housing and the details required by Home Condition Reports.

It is important to stress that although Journal of Building Appraisal is produced with the quality associated with that of a peer-reviewed journal it is not an academic publication. The Journal seeks contributions from anyone with a professional or research interest in the appraisal of the built environment. The overriding principle for all published material is that it must be authoritative, rigorous and of direct relevance to the day-to-day practice of professionals working in the field. Along with 'advertorials', impenetrable, theoretical material with little or no relevance to the real world (so often published by academic journals) will not be considered.

\section{OPPORTUNITIES FOR YOU TO CONTRIBUTE}

The Journal also seeks to reflect the tremendous sense of community in the professions which make up the building appraisal sector by providing a high degree of interactivity to its readers. We want to hear from subscribers 'in the front line' and give readers an unparalleled opportunity to share the latest thinking and best practice techniques with their counterparts in the industry. First and foremost we welcome the submission of conventional papers offering solutions to the issues professionals face in their day-to-day work. However, we realise that not everyone has the time to dedicate to writing a paper. To that end, a letters page will be published in future issues of the Journal, and a message board will be made available through the Journal's website. This exclusive club is open only to subscribers and is intended as a forum for them to discuss the latest developments and share their experience, questions, ideas, problems and solutions with their peers. Instructions on how to access the online message board can be obtained from the Editor and will also appear in the next issue of the Journal. Letters should be sent direct to the editor at the email address below. Just a selection of the forms they might take include:

- A 'call to arms' on a key issue. Is there one you believe the building appraisal profession should be tackling more aggressively or in a different way to the norm? Perhaps raising the status of building surveying worldwide or the campaign against Financial Services Authority regulation of insurance mediation activity?

- Your thoughts on a recent development either within the industry, such as an update to building regulations or a landmark legal case.

- A request for sources of information or the benefit of other readers' experience on key issues, for instance on the use of instrumentation in practice.

- A response to papers and letters published in the Journal. Do you agree with their conclusions or do you feel it vital that alternative perspectives are considered/developed? Certain papers published in the Journal (such as the one by Ralph Burkinshaw on wall base damp in this issue) make direct invitations to readers to respond with accounts of their own experience so that the authors subsequently develop follow-up papers based upon those responses. 
- A call for papers and research projects on specific topics to be published in future issues.

This, then, is our mission for Journal of Building Appraisal. A mission which promises to be as challenging as it is exciting. The development of a professional journal thrives on the input of its readers so we, not to mention your peers, look forward to hearing from you.

Simon Beckett

Publishing Editor

February 2005

E-mail: simon@hspublications.co.uk

\section{Notes}

1. Office of the Deputy Prime Minister

http://www.odpm.gov.uk/stellent/groups/odpm_housing/documents/page/odpm_house_026902.hcsp 